\title{
НАЛОГОВАЯ БЕЗОПАСНОСТЬ ТЕРРИТОРИИ И ЕЕ ОБЕСПЕЧЕНИЕ В УСЛОВИЯХ РАЗВИТИЯ ЦИФРОВОЙ ЭКОНОМИКИ *
}

\author{
(c) 2020 Шемякина Марина Сергеевна \\ кандидат экономических наук, доцент кафедры бухгалтерского учета, налогов \\ и экономической безопасности \\ Поволжский государственный технологический университет, Россия, Йошкар-Ола \\ РИНЦ SPIN-код: 9684-5229 \\ ORCID: https://orcid.org/0000-0003-3515-2680 \\ E-mail: sh.marina.s@gmail.com
}

В статье приводится обоснование необходимости оценки налоговой безопасности публичноправового образования в условиях развития цифровой экономики. Научная значимость исследований, обозначенных в статье направлений такой оценки, заключается в комплексном исследовании налоговой безопасности как составляющей национальной безопасности страны, а также в развитии методологических основ ее обеспечения.

Ключевые слова: налоговая безопасность, налоговое администрирование. циффровая экономика, угрозы, риски, big data, индекс налоговой безопасности, стратегия

\section{Введение}

Наиболее значимыми с точки зрения научнотехнологического развития Российской Федерации большими вызовами являются исчерпание возможностей экономического роста России на фоне формирования цифровой экономики, а также новые внешние угрозы национальной безопасности и усиление их взаимосвязи с внутренними угрозами национальной безопасности. Поиск эффективных инструментов ответа на них - актуальное направление современных научных исследований.

Одним из направлений национальной программы «цифровая экономика Российской Федерации» является цифровизация государственного управления. В паспорте данной программы определено, что до 31.12.2024 г. должна быть «сформирована цифровая платформа для взаимодействия в сфере стратегического управления в целях согласованности действий участников стратегического планирования на всех уровнях государственного управления в достижении стратегических приоритетов». Следует отметить, что цифровая экономика - это в первую очередь, экономика данных. Данные в цифровой форме являются ключевым фактором производства во всех сферах социально-экономической деятельности, что повышает конкурентоспособность страны, качество жизни граждан, обеспечивает экономический рост и национальный суверенитет. При этом стратегическое планирование, на наш взгляд, не возможно без анализа таких данных, которые в свою очередь также участвуют и в оценке налоговой безопасности публичноправовых образований.

Развитие государства невозможно без обеспечения его национальной безопасности, одной из составляющей которой является налоговая безопасность. Это позволяет сохранить суверенитет, территориальную целостность, способность реагировать на возникающие опасности и угрозы. В настоящее время Российская Федерации уверено идет по пути цифровизации. Реализация соответствующих положения Национальной программы «Цифровая экономика Российской Федерации» требует исследования угроз экономической безопасности (как неотъемлемой части национальной безопасности страны) именно с позиций внедрения цифровых технологий. В связи с этим, проверка фундаментальной гипотезы относительно повышения уровня национальной безопасности в связи с цифровизацией страны, в том числе исследование и прогнозирование динамики основных и второстепенных ситуационных рисков и оценка влияния факторов, формирующих угрозы

\footnotetext{
* Работа выполнена в рамках гранта Российского фонда фундаментальных исследований РФФИ 19-010-00620 А «Методология многоуровневого мониторинга и управления налоговой безопасности региона в целях обеспечения социальных обязательств государства в условиях бюджетного дефицита»
} 
налоговой безопасности территории в связи с применением цифровых технологий налогового администрирования представляется весьма актуальным.

Теоретические и практические аспекты сущности налоговой безопасности с разной степенью полноты рассматривались в трудах Р.С.Бекова， Б.В.Воронцовой， В.А.Дворянкова, А.Н.Литвиненко, О.А.Мироновой. Е.А. Олейникова, В.П. Очередько, Н.А. Пименовой, В.К. Сенчагова, И.Ю.Тимофеевой, Т.Ю.Феофиловой, А.А.Фелюст, А.А.Цвилий- Буклановой, Е. В.Черниковой и других. Основными направлениями исследований, связанных с налоговой безопасностью в настоящее время являются вопросы ее обеспечения на уровне предприятия. Однако, многие проблемные вопросы всё еще требуют осмысления и поиска новых научных подходов. Так, налоговой безопасности как подсистеме экономической безопасности на уровне государства, региона и его муниципальных образований в существующих исследованиях уделено недостаточное внимание. Остается малоизученным актуальный вопрос оценки налоговой безопасности в условиях развития цифровой экономики, а также разработки стратегии ее обеспечения.

В трудах ученых других стран налоговая составляющая в основном исследуется в рамках обеспечения экономической безопасности территории. Например, Institution for Social and Policy Studies (New Haven) производит расчет индекса экономической безопасности. Другим подходом является исследование налоговой безопасности не на государственном уровне, а на уровне хозяйствующего субъекта. Так, IRS США налоговую безопасность рассматривает с позиции налогоплательщика и основывается «на усовершенствованных процедурах аутентификации, улучшенном обмене информацией, повышенной кибербезопасности и расширении образования и охвата населения».

\section{Материалы и методы}

Следует отметить, что методология обеспечения налоговой безопасности территории в условиях развития цифровой экономики практически не исследуется современными учеными- налоговедами. Однако, определение эффективных методов ее обеспечения и выявления угроз является одним из условий долгосрочной сбалансированности бюджетов и разработки долгосрочной бюджетной стратегии, а также повышения результативности регулирования финансово-бюджетной сферы. Это обусловило выявление основных направлений исследования для дальнейшей разработки методологии обеспечения налоговой безопасности в условиях развития цифровой экономики. На наш взгляд, к ним следует отнести:

\section{1. Блокчейн технологии. Big data.}

Методология идентификации и нивелировании угроз налоговой безопасности территории должна строиться на основе анализа механизма применения блокчейн - технологий в качестве инструмента ее обеспечения, а также возможностям аналитической работы ФНС России с Big data, аккумулируемым в системах АИС налог и АСК НДС. При этом разработка аналитического обеспечения - развитие методического инструментария оценки индикаторов налоговой безопасности территории, должно осуществляться на основе аккумулируемой налоговыми органами BIG DATA, содержащихся в информационных аналитических системах, а также полученных в результате межведомственного обмена.

Со стороны бизнеса в настоящий момент только формируется экосистема аналитических продуктов по обработке Big data, что же касается государства, то такая система по факту уже создана и находится в руках налоговых органов. Это обуславливает необходимость поиска новых эффективных направлений по использованию уже имеющихся больших данных и разработки инновационных инструментов их обработки. Например, на рисунке 1 представлены данные, аккумулируемые налоговыми органами от продавцов, работающих с онлайн кассой.

Это достаточно большой массив данных, требующий обработки. С одной стороны, налоговый орган получает информацию о структуре потребления товаров и услуг как в разрезе обобщенных групп: пищевые, одежда и.т.д., так и в разрезе наименований: марка, товар и.др. С другой - мы можем оценить расходы физических лиц сопоставив их с налоговой базой по НДФЛ и попытаться произвести оценку латентной (скрытой) налоговой базы.

2. Оценка рисков и идентификация внешних и внутренних угроз налоговой безопасности территории в условиях цифровизации данных налогового администрирования.

На сегодняшний день обработка больших данных, аккумулируемых ФНС, производится, в 


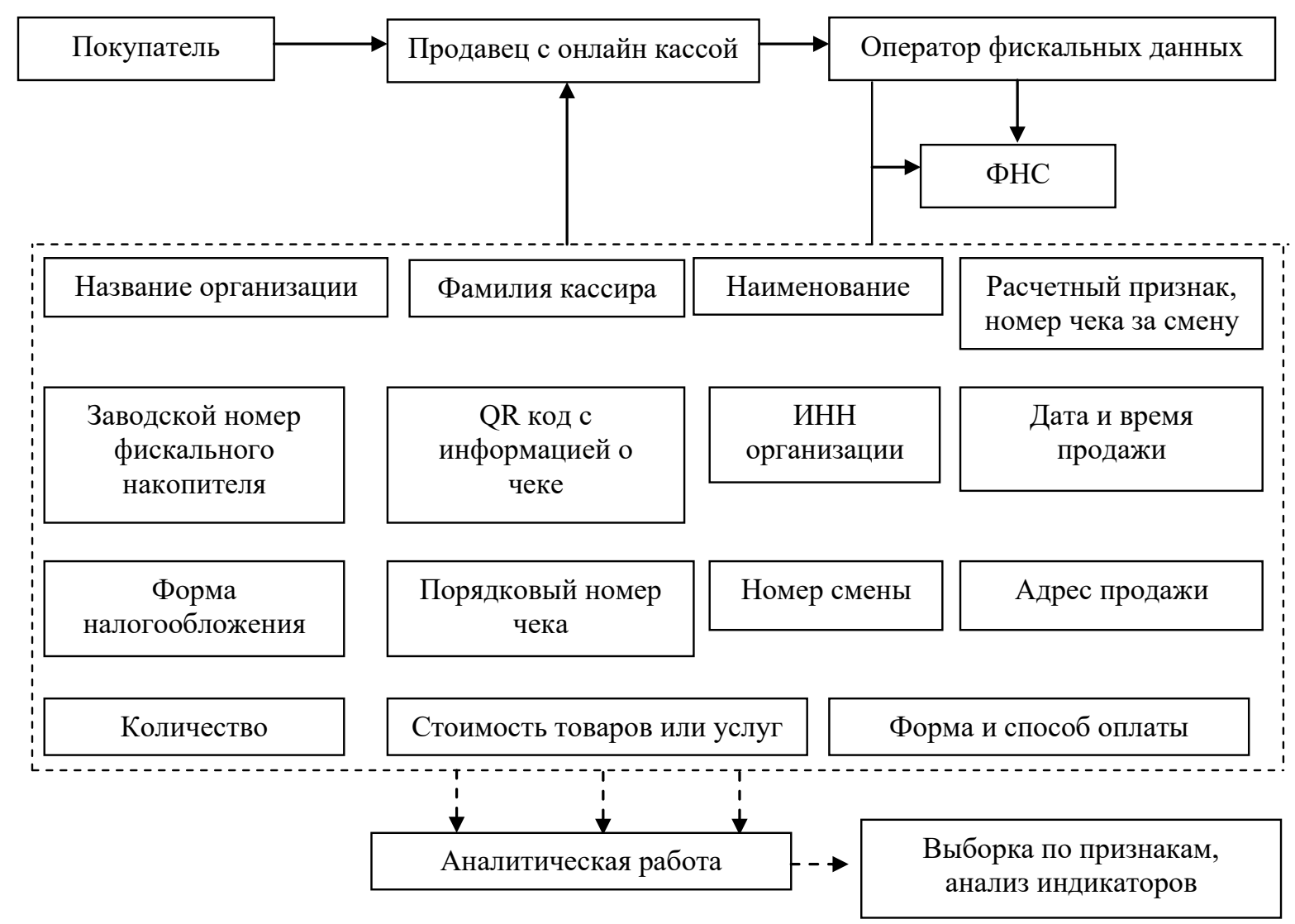

Рисунок 1. Логическая модель передачи данных в ФНС Источник: составлено автором

том числе, в программном продукте АСК «НДС». Благодаря внедрению данной системы, налоговые органы могут выявлять риски, формирующие одну из угроз налоговой безопасности территории- недостаточная сформированность налогового потенциала публично-правового образования по причине изъятия из бюджета налога на добавленную стоимость по сомнительным операциям. Указанный программный продукт распределяет всех налогоплательщиков, представивших налоговые декларации, на три группы по принципу «светофора»: высокий (красный), средний (желтый), низкий (зеленый) риски. Такое распределение происходит автоматически на основе большого количества критериев, заложенных в систему. При этом производится анализ цепочки контрагентов с целью поиска разрывов в уплате НДС в бюджетную систему, схема такого анализа представлена на рисунке 2.

Качественная аналитическая работа позволяет оценить степень «чистоты» администрируемой среды, выявить риски и оценить угрозы налоговой безопасности публично-правового образования.

Следует отметить, что ФНС обладает большими возможностями для осуществления продвинутой аналитики Big data.Это обусловлено, в первую очередь тем, что в режиме реального времени формируется массив данных объединяющих сведения, полученные из онлайн ккт, маркировки товаров, реестра населения и реестра органов ЗАГС. Применение различных современных цифровых технологий и методов и их постепенное улучшение позволит в будущем существенно уменьшить теневой сектор или избавиться от него совсем за счет повышения прозрачности показателей деятельности налогоплательщиков.

3. Разработка экономико-математической модели налоговой безопасности региона и его муниципальных образований.

Разработку следует осуществлять на основе полученных результатов обобщенной модели налоговой безопасности с определением роли ее основных компонентов в величинах базовых 


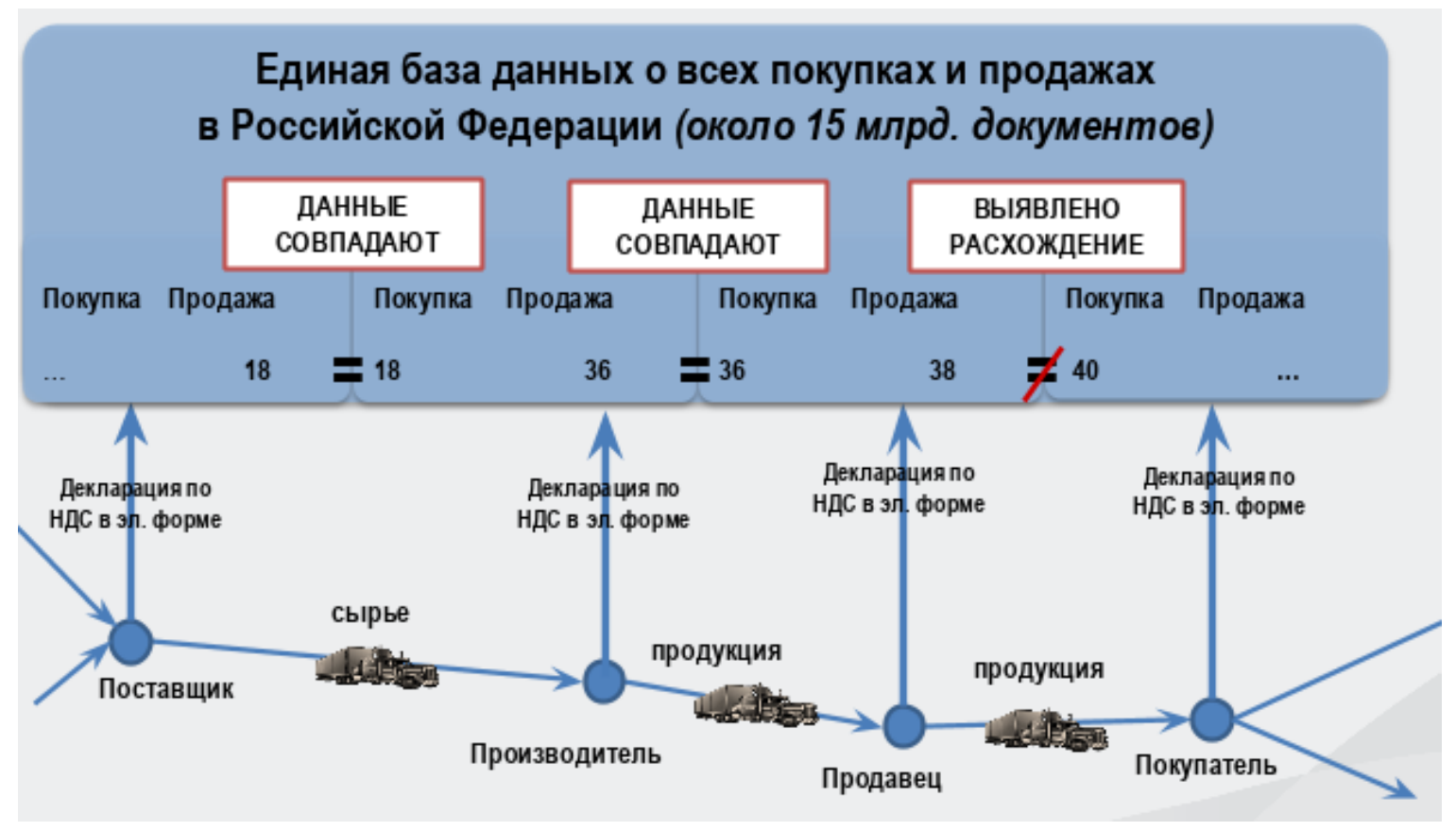

Рисунок 2. Схема расширенного декларирования НДС.

Источник: Презентация зам. начальника контрольного управления ФНС России Новоселова К. В. Электронный ресурс. Режим доступа- URL: https://drive.google.com/file/d/1w8kbZMxMO3-Up6D7sR9n3ZXFWDPA-_h9/view

параметров рисков и сопутствующих им неблагоприятных последствий, а также построение сценариев неблагоприятных событий и количественная оценка рисков через параметры главных инициирующих и поражающих факторов.

4. Разработка стратегии обеспечения налоговой безопасности региона с учетом выявленных рисков, формирующих угрозы необеспеченности бюджетов налоговыми доходами.

Разработка стратегии налоговой безопасности территории в условиях развития цифровой экономики, на наш взгляд, должна осуществляться с учетом:

- выявления основных тенденций становления и развития российской налоговой политики с учетом обеспечения безопасности публично-правового образования в условиях развития цифровой экономики;

- анализа внутренних и внешних угроз налоговой безопасности публично-правового образования;

- разработки методического обеспечения и стратегии налоговой безопасности региона и его муниципальных образований.

5. Разработка индекса налоговой безопасности территории с целью его постоянного мониторинга на основе аналитики Big data, аккумулируемых налоговыми органами.
На наш взгляд, индекс налоговой безопасности представляет собой индикатор, с помощью которого можно производить оценку состояния устойчивости публично-правового образования с целью проверки наличия угрозы необеспеченности бюджетов всех уровней налоговыми доходами. Это обуславливает выбор показателей для проведения такой оценки, в основе которой лежит методика анализа иерархий и расчета интегрального показателя.

Интегральная оценка налоговой безопасности может осуществляться в разрезе 5 блоков выделенных нами индикаторов:

1. Индикаторы, характеризующие поступление налогов и сборов в бюджетную систему:

Коэффициент роста собираемости налогов, коэффициент роста налоговых поступлений.

2. Индикаторы, характеризующие состояние налоговой базы территории:

Коэффициент роста суммы выпадающих налогов в связи с применением льгот, коэффициент роста налоговой базы

3. Индикаторы, характеризующие налоговую задолженность:

Коэффициент роста задолженности/урегулированной задолженности перед бюджетом.

4. Индикаторы, характеризующие результаты налогового контроля: 
Коэффициент результативности проверок, показатель удельного веса дополнительно начисленных сумм налоговых платежей к общему объему налоговых поступлений.

5. Индикаторы, характеризующие социально-экономическое положение региона:

ВРП, Индекс потребительских иен, Налоговая нагрузка на ВРП

В каждом блоке следует рассмотреть не более 3-4 характерных показателей, оценив количественно их изменения. При этом для такого анализа могут рассчитываться коэффициенты роста или прироста. После чего необходимо на основе попарного сравнения групп показателей выбрать весовые коэффициенты и определить сводный показатель группы. Сумма сводных показателей каждого выделенного нами блока определяет интегральный показатель налоговой безопасности территории. После чего на основе анализа полученного значения и его сравнения с коридором значений интегрального показателя следует сделать вывод о состоянии налоговой безопасности публично-правового образования.

\section{Научные результаты}

Научная значимость исследования обозначенных в статье направлений заключается в комплексном исследовании налоговой безопасности как составляющей национальной безопасности страны, а также в развитии методологических основ обеспечения (оценки, управления, мониторинга) налоговой безопасности на уровне различных территориальных образований в условиях развития цифровой экономики. Решение данной проблемы позволит:

Во-первых, своевременно выявлять зоны риска отклонения индикаторов налоговой безопасности от установленного «безопасного» уровня,

Во-вторых, правильно идентифицировать угрозы налоговой безопасности,

В-третьих, произвести быструю оценку выявленным угрозам и, в-четвертых, незамедлительно принять меры к обеспечению допустимого уровня налоговой безопасности.

\section{Библиографический список}

1. Миронова О. А., Шемякина М. С. Основы и взаимосвязь категорий» экономическая безопасность» и» налоговая безопасность» //Инновационное развитие экономики. - 2015.- № . 4.- С. 125-131.

2. Murzina, E.A., Valerievna, Y.T., \& Shemyakina M.S. Factors of strategic management of the tax potential of the region. Academy of Strategic Management Journal, 2019, 18(5). URL: https://www.abacademies.org/articles/ factors-of-strategic-management-of-the-tax-potential-of-the-region-8470.html

3. Shemyakina, M.S., Murzina, E.A., \& Yalyalieva, T.V. (2019). Management of the territory tax potential to ensure its tax security. Regional Science Inquiry, 11(2), 2019, 59-72.

4. Презентация доклада зам. начальника контрольного управления ФНС России Новоселова К. В. Электронный ресурс. Режим доступа- URL: https://drive.google.com/file/d/1w8kbZMxMO3-Up6D7sR9n3ZXFWDPA-_h9/view 